\title{
A Case Report on: Non-Symptomatic SARS-CoV-2 Results in Adverse Neurological Symptoms - Von Willebrand Factor (VWF) May Have A Casual or Causal Link
}

\author{
Sushma Chodisetty ${ }^{1}$, Ganesh Elumalai ${ }^{2 *}$
}

${ }^{1}$ Casulty Medical Officer, Trust Hospital, Kakinada, Andhra Pradesh, India

${ }^{2}$ Professor, Department of Anatomy and Neuroscience, Texila American University, Zambia, South Africa

\begin{abstract}
Neurological manifestations are various and prevalent in SARS-CoV-2. Recent clinical evidences are suggests various silent neurological involvements are observed and it is an important aspect of this disease. The underlying mechanisms may includes both endothelial cell dysfunction and von-Willebrand factor inflammatory responses. Further studies must be conducted to explore the role of neurological manifestations in SARS-CoV-2 progression and must verify their underlying mechanisms. Many patients are developed a mild-to-moderate form of Neurological symptoms in the SARS-CoV-2 disease. SARS-CoV-2 mortality risk is higher in elderly patients and in patients with cerebrovascular diseases and coronary vascular diseases. Molecular mechanisms which underlie these risks are not yet understood for SARS-CoV-2. Here we discuss a possible association of SARS-CoV-2 complications with von Willebrand factor (VWF) level and endothelial damage. Von Willebrand factor is an important prognostic indicators of endothelial dysfunction and its level varies depends on sex and age. Significantly, a drug chloroquine, that showed potential efficacy for SARS-CoV-2 treatment, can influence VWF secretion and consequently its level and activities. We propose that varies in the VWF levels and its activities might be predictors of the SARS-CoV-2 morbidity and mortality, moreover the VWF might be involved in the pathogenesis of the disease. We also suggest that a comprehensive study of VWF level in SARS-CoV-2 positive groups of people with mild and severe course of the disease should be undertaken.

Keywords: SARS-CoV-2, Acute Respiratory Distress syndrome, von Willebrand factor, Angiotensin Converting Enzymes -2, Endothelial dysfunction.
\end{abstract}

Copyright @ 2020: This is an open-access article distributed under the terms of the Creative Commons Attribution license which permits unrestricted use, distribution, and reproduction in any medium for non-commercial use (NonCommercial, or CC-BY-NC) provided the original author and source are credited.

\section{INTRODUCTION}

A 50yrs female patient admitted in Emergency Room (ER) presenting with stroke due to CerebroVascular-Accident (CVA), MRI investigation results in multiple cerebral infarcts. Upon regular COVID scanning for all the hospital admissions during this period, we found SARS-CoV-2 IgM, IgG and swab investigations were positive for this patient. And, CT thorax showed $80 \%$ lung involvement but, she does not need any oxygen or breathing complaints before. The laboratory findings of $\mathrm{IgG}$ positive shows, possibilities of she might have affected with SARS-CoV-2 few weeks back with $80 \%$ lung involvement and recovered spontaneously without medicines but went for microthrombosis complications as she was not on any anticoagulant. CT findings may take more time to disappear to pneumonia in chest X-ray.

\section{DiscuSSION}

The current observation, postulate an instinct with a possible correlation of von Willebrand factor
(VWF) for her multiple cerebral infarcts. VWF is one of the factors in blood clotting, secreted by endothelial cells lining the blood vessels, stored in Weibel-palade bodies found in endothelial cells and secreted in the form of deciliter (IU/dL) [1]. Replication of SARSCoV-2 virus in endothelial cells leads to damage of the blood vessel wall, and results in increase the level of VWF in blood. VWF will try to patch up the defect in vessel wall, thus increasing the risk of thrombosis. Most deaths in SARS-CoV-2 are associated with clotting. SARS-CoV-2 presents in different ways such as symptoms, severity, transmission etc. One of the possible causes may be different levels of VWF in blood. Severe course of SARS-CoV-2 may be associated with high level of VWF $[1,2]$.

Main function of VWF is to form platelet adhesion frame work. Low levels ( $<50 \mathrm{IU} / \mathrm{dL})$ of VWF results in hereditary blood disease called vonWillebrand disease causing spontaneous bleeding. The level of VWF varies, higher in men than women, higher in elderly than young. Interestingly it is found in low level in person with "O" blood group than others. Acute 
Respiratory Distress syndrome (ARDS) also found to be associated with VWF level, the thrombosis occurs in capillaries surrounding alveoli [2, 3].

Levels and activity of VWF is an important predictor of morbidity and mortality. High level patients require ventilation or have thrombo-embolic complications. The normal level varies from 50-200 IU/dL in severe SARS-CoV-2 patients it may rise up to $555 \mathrm{IU} / \mathrm{dL}[2,3]$. Though the endothelial cells have large number of Angiotensin Converting Enzymes -2 (ACE-2) receptors, the level of ACE2 has inverse correlation with the development of ARDS caused by the closely-related SARS-CoV-2 virus. Interaction of SARS viruses with ACE2 was proposed to inhibit ACE2 activity and down regulate ACE2 expression on the cell surfaces [4-6].

Consequently, this should promote ACE1/ACE2 imbalance and increase in the Angiotensin II level [7]. Interestingly, VWF might be a missing link in Angiotensin II-mediated endothelial dysfunction [7, 8]. For instance, VWF gene silencing counteracts Angiotensin II-dependent endothelium dysfunction in a porcine model [9]. In addition, the protective role of Angiotensin (1-9) has been linked to the decrease in VWF expression [10]. It is an important question whether a misbalanced in the renin-angiotensin system upon SARS-CoV-2 infection can lead to a change in VWF production, processing or secretion in the endothelium. Recent reports showing significantly elevated VWF level and activity in a small cohort of intubated SARS-CoV-2 patients is in accord with idea that SARS-CoV-2 might provoke endothelial activation and dysfunction [11-13]. It is of great interest if hypercoagulability, ARDS and other symptoms observed in SARS-CoV-2 patients could be explained through VWF-dependent mechanism.

\section{CONCLUSION}

Summarizing these facts, we hypothesize that VWF level or activity might be used as a predictor of SARS-CoV-2 symptoms severity. We also suggest that comprehensive studies of VWF level or activity correlations with SARS-CoV-2 symptoms and mortality rate must be performed. In addition, it can be assumed that medication improving the endothelium function and antagonizing inflammation in vessels could be beneficial for SARS-CoV-2 therapy and as a prophylaxis of severe complications of SARS-CoV-2.

\section{REFERENCES}

1. Kawecki C, Lenting PJ, Denis CV. von Willebrand factor and inflammation. J Thromb Haemost. 2017; 15(7):1285-1294. https://doi.org/10.1111/jth.13696.

2. Ware LB, Eisner MD, Thompson BT, Parsons PE, Matthay MA. Significance of von Willebrand factor in septic and nonseptic patients with acute lung injury. American journal of respiratory and critical care medicine. 2004 Oct 1;170(7):766-72.

3. El Wahsh R, Amin S, Essa E. Diagnostic value of von Willebrand factor (VWF) in patients suffering from respiratory distress. Eur Respir J. 2011; 38:1686.

4. Kuba K, Imai Y, Rao S, Gao H, Guo F, Guan B, Huan Y, Yang P, Zhang Y, Deng W, Bao L. A crucial role of angiotensin converting enzyme 2 (ACE2) in SARS coronavirus-induced lung injury. Nature medicine. 2005 Aug;11(8):875-9.

5. Imai Y, Kuba K, Rao S, Huan Y, Guo F, Guan B, Yang P, Sarao R, Wada T, Leong-Poi H, Crackower MA. Angiotensin-converting enzyme 2 protects from severe acute lung failure. Nature. 2005 Jul;436(7047):112-6.

6. Zhang H, Penninger JM, Li Y, Zhong N, Slutsky AS. Angiotensin-converting enzyme 2 (ACE2) as a SARS-CoV-2 receptor: molecular mechanisms and potential therapeutic target. Intensive care medicine. 2020 Apr;46(4):586-90.

7. Tignanelli CJ, Ingraham NE, Sparks MA, Reilkoff R, Bezdicek T, Benson B, Schacker T, Chipman JG, Puskarich MA. Antihypertensive drugs and risk of COVID-19?. The Lancet Respiratory Medicine. 2020 May 1;8(5):e30-1.

8. Sriram K, Insel PA. A hypothesis for pathobiology and treatment of COVID-19: the centrality of ACE1/ACE2 imbalance. Br J Pharmacol. 2020. https://doi.org/10.1111/bph.15082.

9. Agostini S, Lionetti V. New insights into the nonhemostatic role of von Willebrand factor in endothelial protection. Can J Physiol Pharmacol. 2017;95(10):1183-1189. https://doi.org/10.1139/cjpp-2017-0126.

10. Dushpanova A, Agostini S, Ciofini E, Cabiati M, Casieri V, Matteucci M, Del Ry S, Clerico A, Berti S, Lionetti V. Gene silencing of endothelial von Willebrand Factor attenuates angiotensin IIinduced endothelin-1 expression in porcine aortic endothelial cells. Scientific reports. $2016 \mathrm{Jul}$ 22;6:30048.

11. Cha SA, Park BM, Kim SH. Angiotensin-(1-9) ameliorates pulmonary arterial hypertension via angiotensin type II receptor. Korean J Physiol Pharmacol. 2018;22(4):447-456 https://doi.org/10.4196/kjpp.2018.22.4.447.

12. Panigada M, Bottino N, Tagliabue P, Grasselli G, Novembrino C, Chantarangkul V, Pesenti A, Peyvandi F, Tripodi A. Hypercoagulability of COVID- 19 patients in intensive care unit. A report of thromboelastography findings and other parameters of hemostasis. Journal of Thrombosis and Haemostasis. 2020 Apr 17.

13. Escher R, Breakey N, Lammle B. Severe COVID19 infection associated with endothelial activation. Thromb Res. 2020;190:62. https://doi.org/10.1016/ j.thromres.2020.04.014. 